\title{
Therapeutic Outcome of Transhepatic Arterial Chemoembolization in Combination with Local Thermal Ablation on large Hepatocellular Carcinoma and Risk Factors
}

G. XINGSHI, B. XUMING*, JI WANG ${ }^{1}$, Y. QIANG AND Z. JIAN

Department of Interventional Medicine, ${ }^{1}$ Department of Oncology, The Second Affiliated Hospital of Soochow University, Suzhou 215000, Jiangsu Province, P. R. China

Xingshi et al.: Treatment of large hepatocellular carcinoma

\begin{abstract}
The aim of this study was to evaluate the outcome of transhepatic arterial chemoembolization in combination with local thermal ablation on large hepatocellular carcinoma, and to analyse risk factors. Ninety patients with large hepatocellular carcinoma admitted to the Second Affiliated Hospital of Soochow University from January 2017 to December 2019 were enrolled to receive transhepatic arterial chemoembolization combined with local thermal ablation. The short-term efficacy was then evaluated and the objective response rate was analysed. According to the short-term efficacy, the patients were assigned into objective response group and control group (no objective response was achieved) and their clinical data were compared. Related risk factors were subjected to univariate analysis and multivariate logistic regression analysis. After transhepatic arterial chemoembolization combined with local thermal ablation, 47 out of 90 patients with large hepatocellular carcinoma achieved an objective response, whereas the remaining 43 patients failed to do so, with an objective response rate of $52.22 \%$. According to univariate analysis, there were significant differences in the diameter, number and clinical stage of tumours, preoperative $\alpha$-fetoprotein level and portal vein tumour thrombus between the two groups, but no significant differences in the age, sex and body mass index. Based on multivariate logistic regression analysis, the tumour diameter of $\geq 7 \mathrm{~cm}$, tumour number of $\geq 2$, clinical stage III-IV, preoperative $\alpha$-fetoprotein level of $\geq 200 \mu \mathrm{g} / \mathbf{l}$ and presence of portal vein tumour thrombus were risk factors affecting the treatment outcomes. Transhepatic arterial chemoembolization in combination with local thermal ablation exerted obvious therapeutic effects on large hepatocellular carcinoma. However, the treatment outcomes are affected by the diameter, number and clinical stage of tumours, preoperative $\alpha$-fetoprotein level and portal vein tumour thrombus. Therefore, corresponding interventional measures should be taken based on the above risk factors.
\end{abstract}

Key words: Epidural anaesthesia, painless delivery, obstetrics

Liver cancer, a common malignancy, has an extremely high incidence rate that makes this disease rank fourth among all tumours, and results in a high risk of death, seriously threatening the life and health of patients ${ }^{[1,2]}$. Transhepatic arterial chemoembolization and local thermal ablation are the major interventional therapies for the clinical treatment of liver cancer ${ }^{[3]}$, but it is hard to treat large hepatocellular carcinoma, a liver tumour with a diameter of $\geq 5 \mathrm{~cm}^{[4]}$. The short-term efficacy of transhepatic arterial chemoembolization and local thermal ablation is poor in some patients and the factors affecting the efficacy need to be determined, so as to further improve the short-term efficacy on patients with large hepatocellular carcinoma. In this study, a retrospective analysis was performed on 90 patients with large hepatocellular carcinoma after transhepatic arterial chemoembolization combined with local thermal ablation, aiming to explore its efficacy in the treatment of large hepatocellular carcinoma and to identify the risk factors for the treatment outcomes.

A total of 90 patients with large hepatocellular carcinoma admitted to the Second Affiliated Hospital of Soochow University from January 2017 to December 2019 were enrolled as the subjects for a retrospective study. Their age range was 30-79 y among which 39 cases were aged $\geq 60$ y and 51 cases were aged $<60 \mathrm{y}$. There were 49 male and 41 female patients. The body mass index (BMI) was $\geq 25 \mathrm{~kg} / \mathrm{m}^{2}$ in 23 cases and $<25 \mathrm{~kg} / \mathrm{m}^{2}$ in 67 cases. Besides, 23 patients experienced portal vein tumour thrombus. Inclusion criteria were ${ }^{[5]}$, 
patients diagnosed with large hepatocellular carcinoma based on imaging examinations, observation of clinical symptoms, pathological diagnosis and a tumour diameter $\geq 5 \mathrm{~cm}$; those with indications for transhepatic arterial chemoembolization and local thermal ablation; those who were informed of and consented to surgical regimens preoperatively, and signed the informed consent document and those with complete clinical data. Exclusion criteria ${ }^{[6]}$ were, patients with complicated severe systemic infection; those with other concomitant malignancies; those previously treated with hepatectomy, liver transplantation, transhepatic artery chemoembolization and ablation; those with mental disorders and those with incomplete clinical data. All patients underwent transhepatic arterial chemoembolization combined with local thermal ablation. With the patients lying supine, the right femoral artery was punctured and a catheter was retained in the target feeding artery for liver tumours. Subsequently, contrast agents were infused, and hepatic tumours were pinpointed. Next, gelatin sponge particles as an embolic agent and lipiodol emulsion were transcatheterally infused into the hepatic artery for embolization. After $1 \mathrm{w}$, local thermal ablation was conducted. Under local infiltration anaesthesia, the patients received ultrasound or CT-guided puncture in the supine position, and an ablation probe was inserted into the central area of the liver cancer lesions. After the voltage and time for ablation were set well, local thermal ablation was performed. After treatment, the short-term efficacy was evaluated, and the objective response rate was calculated based on objective response rate $=$ (Cases with complete response $(\mathrm{CR})+$ Cases with partial response $(\mathrm{PR})$ )/total number of cases $\times 100 \%$. Evaluation criteria were, CRdisappearance of liver tumour lesions and no new lesions; PR- $a \geq 30 \%$ decrease in the area of liver tumour lesions; SD- stable disease a $<30 \%$ decrease or $<20 \%$ increase in the area of tumour lesions; PDprogressive disease $\mathrm{a} \geq 20 \%$ increase in the area of liver tumour lesions and one or more new lesions ${ }^{[7]}$. According to the short-term efficacy observed, patients were divided into objective response group ( $\mathrm{CR}+\mathrm{PR})$ and control group (SD+PD). The clinical data were compared between the two groups, and the risk factors for the efficacy of transhepatic arterial chemoembolization combined with local thermal ablation in the treatment of patients with large hepatocellular carcinoma were determined by univariate analysis and multivariate logistic regression analysis. The following indicators were analysed, age ( $\geq 60 \mathrm{y}$ old or $<60$ y old), sex (male/female), BMI ( $\geq 25 \mathrm{~kg} / \mathrm{m} 2$ or $<25 \mathrm{~kg} / \mathrm{m} 2$ ), tumour diameter $(\geq 7 \mathrm{~cm}$ or $<7 \mathrm{~cm})$, number of tumour $(\geq 2$ or $<2$ ), clinical stage (stage I-II or stage III-IV), preoperative $\alpha$-fetoprotein level ( $\geq 200 \mu \mathrm{g} / 1$ or $<200 \mu \mathrm{g} / \mathrm{l}$ ) and portal vein tumour thrombus (presence or absence). All data were statistically analysed by SPSS 26.0 software. The numerical data were expressed as $\mathrm{n}$ and subjected to the $\chi^{2}$ test. The quantitative data were represented as $(\bar{x} \pm s)$ and subjected to the $t$ test. The variables with statistical significance in univariate analysis were included in multivariate logistic regression analysis. $\mathrm{p}<0.05$ was considered statistically significant. After transhepatic arterial chemoembolization combined with local thermal ablation, 47 out of 90 patients with large hepatocellular carcinoma experienced an objective response (19 cases of CR and 28 cases of PR), but the remaining 43 patients had no objective response ( 30 cases of SD and 13 cases of PD). The objective response rate was $52.22 \%$. According to univariate analysis, the diameter, number and clinical stage of tumours, preoperative $\alpha$-fetoprotein level and portal vein tumour thrombus were significantly different between the two groups $(p<0.05)$, but there were no significant differences in the age, sex and BMI (Table 1). The variables with $\mathrm{P}<0.05$ in the univariate analysis were included into a multivariate logistic regression model and assigned (Table 2). The tumour diameter of $\geq 7 \mathrm{~cm}$, tumour number of $\geq 2$, clinical stage III-IV, preoperative $\alpha$-fetoprotein level of $\geq 200 \mu \mathrm{g} / 1$ and presence of portal vein tumour thrombus were risk factors for the treatment outcomes (Table 3).Primary liver cancer, one of the most common malignancies in China, has higher incidence and mortality rates, and once it occurs, the patients will have hepatic pain and other symptoms ${ }^{[8]}$. In the early stage, primary liver cancer is lowly malignant, and with disease aggravation, the tumors have a gradually enlarged volume and gradually invade the surrounding tissues, severely endangering the life safety of patients ${ }^{[9]}$. Large hepatocellular carcinoma, a type of liver cancer with a diameter $\geq 5 \mathrm{~cm}$, should be actively treated for the large tumour diameter and poor prognosis ${ }^{[10]}$. In recent years, transhepatic arterial chemoembolization and local thermal ablation have achieved certain efficacy in treating primary liver cancer. Transhepatic arterial chemoembolization, as an interventional therapy, mainly embolizes the hepatic artery through puncturing, intubating and transcatheterally infusing gelatine sponge particles and lipiodol emulsion into the hepatic artery, thereby blocking the blood supply to liver tumours from the hepatic artery, inducing gradual 
TABLE 1: UNIVARIATE ANALYSIS RESULTS

\begin{tabular}{|c|c|c|c|c|c|}
\hline Factor & & Objective response group $(n=47)$ & Control group $(n=43)$ & $x^{2}$ & $p$ \\
\hline \multirow{2}{*}{ Age } & $\geq 60 \mathrm{y}$ & $21(44.68)$ & $18(41.86)$ & \multirow{2}{*}{0.073} & \multirow{2}{*}{0.787} \\
\hline & $<60 y$ & $26(55.32)$ & $25(58.14)$ & & \\
\hline \multirow{2}{*}{ Gender } & Male & $26(55.32)$ & $23(53.49)$ & \multirow{2}{*}{0.030} & \multirow{2}{*}{0.862} \\
\hline & Female & $21(44.68)$ & $20(46.51)$ & & \\
\hline \multirow{2}{*}{ BMI } & $\geq 25 \mathrm{~kg} / \mathrm{m}^{2}$ & $13(27.66)$ & $10(23.26)$ & \multirow{2}{*}{0.229} & \multirow{2}{*}{0.632} \\
\hline & $<25 \mathrm{~kg} / \mathrm{m}^{2}$ & $34(72.34)$ & $33(76.74)$ & & \\
\hline \multirow{2}{*}{ Tumour diameter } & $\geq 7 \mathrm{~cm}$ & $24(51.06)$ & $11(25.58)$ & \multirow{2}{*}{6.136} & \multirow{2}{*}{0.013} \\
\hline & $<7 \mathrm{~cm}$ & $23(48.94)$ & $32(74.42)$ & & \\
\hline \multirow{2}{*}{ Tumour number } & $\geq 2$ & $12(25.53)$ & $3(6.98)$ & \multirow{2}{*}{5.567} & \multirow{2}{*}{0.018} \\
\hline & $<2$ & $35(74.47)$ & $40(93.02)$ & & \\
\hline \multirow{2}{*}{ Tumour stage } & $\mid \sim \|$ & $28(59.57)$ & $37(86.05)$ & \multirow{2}{*}{7.844} & \multirow{2}{*}{0.005} \\
\hline & III IV & $19(40.43)$ & $6(13.95)$ & & \\
\hline \multirow{2}{*}{$\begin{array}{l}\text { Preoperative } \\
\alpha \text {-fetoprotein level }\end{array}$} & $\geq 200 \mu \mathrm{g} / \mathrm{l}$ & 27 (57.45) & $13(30.23)$ & \multirow{2}{*}{6.736} & \multirow{2}{*}{0.009} \\
\hline & $<200 \mu \mathrm{g} / \mathrm{l}$ & $20(42.55)$ & $30(69.777)$ & & \\
\hline \multirow{2}{*}{$\begin{array}{l}\text { Portal vein tumour } \\
\text { thrombus }\end{array}$} & Yes & $18(38.30)$ & $5(11.63)$ & \multirow{2}{*}{8.396} & \multirow{2}{*}{0.004} \\
\hline & No & $29(61.70)$ & 38 (88.37) & & \\
\hline
\end{tabular}

Numbers in parenthesis reprecents percentage

TABLE 2: VARIABLE ASSIGNMENTS

$\begin{array}{lc}\text { No. } & \text { Variable } \\ \text { Y } & \text { Treatment outcome } \\ \text { X1 } & \text { Tumour diameter } \\ \text { X2 } & \text { Tumour number } \\ \text { X3 } & \text { Tumour stage } \\ \text { X4 } & \text { Preoperative } \alpha \text {-fetoprotein level } \\ \text { X5 } & \text { Portal vein tumour thrombus }\end{array}$

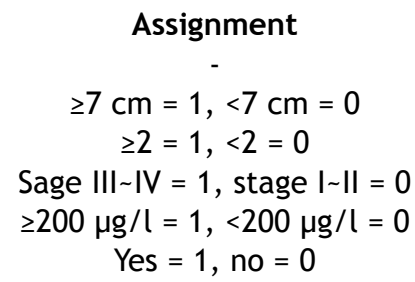

\section{Assignment}

$\mathrm{cm}=1,<7 \mathrm{~cm}=0$

Yes $=1$, no $=0$

TABLE 3: MULTIVARIATE LOGISTIC REGRESSION ANALYSIS RESULTS

\begin{tabular}{lcccccc}
\hline Factor & $B$ & SE & Wald & $\boldsymbol{P}$ & OR & 95 \% Cl \\
\hline Tumour diameter $\geq 7 \mathrm{~cm}$ & 0.357 & 1.389 & 4.283 & 0.004 & 2.418 & $1.245 \sim 3.098$ \\
Tumour number $\geq 2$ & 0.354 & 1.362 & 4.321 & 0.006 & 2.601 & $1.409 \sim 3.120$ \\
Tumour stage III IV & 0.321 & 1.356 & 4.305 & 0.003 & 2.549 & $1.325 \sim 3.247$ \\
Preoperative $\alpha$-fetoprotein level $\geq 200 \mu \mathrm{g} / \mathrm{l}$ & 0.367 & 1.337 & 4.287 & 0.002 & 2.731 & $1.438 \sim 3.046$ \\
Portal vein tumour thrombus & 0.380 & 1.345 & 4.236 & 0.002 & 2.790 & $1.457 \sim 3.072$ \\
\hline
\end{tabular}

shrinkage of liver tumours, decreasing tumour volume and prolonging tumourprogression ${ }^{[11-13]}$. L i k e w is e, local thermal ablation is another interventional therapy. During this procedure, microwaves or radiofrequency currents are mainly used to agitate liver tumours, and then heat is generated by the resultant friction. At a certain temperature, tumour tissue that is less resistant to heat than normal tissue gets gradually ablated. As a result, the mitochondria and lysosomes in cancer cells are destroyed, with gradual apoptosis of cancer cells, thereby reducing cancer ${ }^{[14-16]}$. In this study, after transhepatic arterial chemoembolization combined with local thermal ablation, 47 out of 90 patients with large hepatocellular carcinoma exhibited an objective response, with an objective response rate of $52.22 \%$. These results suggested that transhepatic arterial chemoembolization combined with local thermal ablation exerted a favourable anticancer effect in patients with large hepatocellular carcinoma and delayed tumour progression. However, the short-term efficacy was far from ideal in some patients and remains to be improved. Identifying the risk factors for efficacy is the key to improving it. In the present study, a retrospective analysis was conducted on the patients with large hepatocellular carcinoma, who had different responses to transhepatic arterial chemoembolization combined with local thermal ablation, and univariate analysis and multivariate logistic regression analysis were performed as well. It was found that the tumour diameter $\geq 7 \mathrm{~cm}$, number of tumour $\geq 2$, clinical stage III-IV, preoperative alpha-fetoprotein level $\geq 200 \mu \mathrm{g} / 1$ and presence of portal vein tumour thrombus were the risk factors for the efficacy of transhepatic arterial chemoembolization combined with local thermal ablation in treating the patients with large hepatocellular carcinoma. The mechanisms of action proposed are as 
follows, the diameter, number and clinical stage of tumours and $\alpha$-fetoprotein levels reflect the tumour progression in patients with liver cancer and the disease is more severe in these patients with tumour diameter of $\geq 7 \mathrm{~cm}$, number of tumour are $\geq 2$, clinical stage III-IV cancer and preoperative $\alpha$-fetoprotein level of $\geq 200$ $\mu \mathrm{g} / \mathrm{l}$ for whom the efficacy of transhepatic arterial chemoembolization combined with local thermal ablation is affected by the proneness to appearance of tumour residuals and incomplete ablation. Portal vein tumour thrombus is a common complication in patients with primary liver cancer, which will aggravate the disease conditions, accelerate the tumour progression and shorten the survival time in patients with primary liver cancer. Therefore, the prognosis after interventional therapies is relatively poor in patients with portal vein tumourthrombus ${ }^{[17]}$.In conclusion, transhepatic arterial chemoembolization combined with local thermal ablation has certain efficacy in treating large hepatocellular carcinoma. However, the treatment outcomes of patients are affected by the diameter, number and clinical stage of tumours, preoperative $\alpha$-fetoprotein level and portal vein tumour thrombus, so the corresponding interventional measures should be taken clinically based on the above risk factors.

\section{Conflict of interest:}

All authors report no conflicts of interest in this work.

\section{REFERENCES}

1. Joskin J, de Baere T, Auperin A, Tselikas L, Guiu B, Farouil G, et al. Predisposing factors of liver necrosis after transcatheter arterial chemoembolization in liver metastases from neuroendocrine tumor. Cardiovasc Interv Radiol 2015;38:37280 .

2. Chao Y, Chung YH, Han G, Yoon JH, Yang J, Wang J, et al. The combination of transcatheter arterial chemoembolization and sorafenib is well tolerated and effective in Asian patients with hepatocellular carcinoma: Final results of the START trial. Int J Cancer 2015;136:1458-67.

3. Hiraoka A, Ishimaru Y, Kawasaki H, Aibiki T, Okudaira T, Toshimori A, et al. Tumor Markers AFP, AFP-L3, and DCP in Hepatocellular Carcinoma Refractory to Transcatheter Arterial Chemoembolization. Oncology 2015;89:167-74.

4. Abdelaziz AO, Nabeel MM, Elbaz TM, Shousha HI, Hassan EM, Mahmoud SH, et al. Microwave ablation versus transarterial chemoembolization in large hepatocellular carcinoma: prospective analysis. Scand J Gastroenterol 2015;50:479-84.

5. Stevens CL, Awad A, Abbas SM, Watters DA. Systematic review and meta-analysis of hepatic resection versus trans arterial chemoembolization for solitary large hepatocellular carcinoma. HPB 2017; 19:653-8.

6. Lee SS, Kim KA, Park MS, Choi SY. MRI findings and prediction of time to progression of patients with hepatocellular carcinoma treated with drug-eluting bead transcatheter arterial chemoembolization. J Korean Med Sci 2015;30:965-73.

7. Takeda A, Koike W, Hayashi S, Imoto S, Nakamura H. Magnetic resonance imaging and 3-dimensional computed tomographic angiography for conservative management of proximal interstitial pregnancy by hysteroscopic resection after Transcatheter Arterial chemoembolization. J Minim InvasGynecol 2015;22:658-62.

8. Huo XH. Clinical study of transcatheter arterial chemoembolization combined with microwave ablation in the treatment of advanced hepatocellular carcinoma. J Cancer Res Ther 2016;12:217-20.

9. Farinati F, Vanin V, Giacomin A, Pozzan C, Cillo U, Vitale A, et al. BCLC stage B hepatocellular carcinoma and transcatheter arterial chemoembolization: a 20 -year survey by the Italian Liver Cancer group. Liver Int 2015;35:223-31.

10. Murotani K, Nakai M, Sato M, Minamiguchi H, Sonomura T, Hosokawa $\mathrm{S}$, et al. change in portal vein hemodynamics after chemoembolization for hepatocellular carcinoma: evaluation through multilevel dynamic multidetector computed tomography during arterial portography. J Comp Assist Tomogr 2015;39:396-400.

11. Hirooka M, Hiraoka A, Ochi H, Kisaka Y, Joko K, Michitaka K, et al. Transcatheter arterial chemoembolization with or without radiofrequency ablation: outcomes in patients with Barcelona clinic liver Cancer stage B hepatocellular carcinoma. Am J Roentgenol 2018;210:891-8.

12. Tang BX, Sheng XN, Chi ZH, Cui CL, Si L, Yan XQ, et al. Efficacy and safety of transcatheter arterial chemoembolization combined with systemic chemotherapy in urothelial carcinoma patients with liver metastasis. Tumor 2018;38:120-5.

13. Alexander ES, Mick R, Nadolski GJ, Mondschein JI, Stavropoulos SW, Soulen MC. Combined chemoembolization and thermal ablation for the treatment of metastases to the liver. AbdominRadiol 2018;43:2859-67.

14. Hatanaka T, Arai H, Kakizaki S. Balloon-occluded transcatheter arterial chemoembolization for hepatocellular carcinoma. World J Hepatol 2018;10:485-95.

15. Sun H, Zhang M, Liu R, Liu Y, Hou Y, Wu C. Endovascular implantation of $125 \mathrm{I}$ seed combined with transcatheter arterial chemoembolization for unresectable hepatocellular carcinoma. Future Oncol 2018;14:1165-76.

16. Zeng JY, Piao XH, Zou ZY, Yang QF, Qin ZL, Chen JB, et $a l$. Cryoablation with drug-loaded bead embolization in the treatment of unresectable hepatocellular carcinoma: Safety and efficacy analysis. Oncotarget 2018;9:7557-66.

17. Zheng N, Wei X, Zhang D, Chai W, Che M, Wang J, et al. Hepatic resection or transarterial chemoembolization for hepatocellular carcinoma with portal vein tumor thrombus. Medicine 2016;95:e3959.

This is an open access article distributed under the terms of the Creative Commons Attribution-NonCommercial-ShareAlike 3.0 License, which allows others to remix, tweak, and build upon the work non-commercially, as long as the author is credited and the new creations are licensed under the identical terms

This article was originally published in a special
issue, "Biomedical Research in Healthcare Setting"
Indian J Pharm Sci 2020:82(3)Spl issue5;93-96

